ELK ASIA PACIFIC JOURNAL OF SOCIAL SCIENCES

ISSN 2394-9392 (Online); DOI: 10.16962/EAPJSS/issn.2394-9392/2014; Volume 2 Issue 1 (2015)

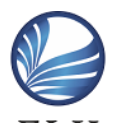

ELK

Asia Pacific Journals

www.elkjournals.com

\title{
USING TYLER'S THEORY OF CURRICULUM MODELLING FOR EFFECTIVE DEVELOPMENT OF ARABIC IN THE CONTEMPORARY NIGERIAN TERTIARY INSTITUTIONS
}

\begin{tabular}{|c|c|}
\hline Kazeem Oluwatoyin Ajape & Yusuf Abdul Azeez \\
\hline $\begin{array}{c}\text { Lecturer \& Head of Department of Arabic, Lagos State } \\
\text { College of Primary Education, Noforija, Epe, Lagos, } \\
\text { Nigeria }\end{array}$ & $\begin{array}{l}\text { Senior Lecturer, Faculty of Syriah and Law, Islamic } \\
\text { Science University of Malaysia (USIM) }\end{array}$ \\
\hline
\end{tabular}

\begin{abstract}
This study attempts to trace the foundation of the teaching and learning of Arabic language as a course of study in the Nigerian tertiary institutions in an effort to revive the curriculum of Arabic language in the light of contemporary challenges for nation building and human development. Hence the study explore the perspectives of students in the Arabic Departments in one of the universities in the South West, Nigeria in order to find indepth solutions to their observations regarding the present state of the programme in the Nigerian tertiary institutions. The process of getting an accurate data for this research was guided by Tyler's theory of curriculum modelling. Efforts were, therefore, made in this paper to identify the grassroots' problems and misconception of the Nigerian Society about the language of Arabic itself, Tyler's theories of curriculum modeling were put into test in order to proffer solution to the fear raised by the students of Arabic Language in Nigeria, and the contemporary effort and approach of the Federal government of Nigeria to enhance the learning of the language in Nigeria were also emphasised. Going by the prevailing circumstances identified in this study, it establishes the fact that the present curriculum is not in conformity with the philosophy and goals of the national policy on education. The study, therefore, proposes a new dimension for the teaching and learning of Arabic language by stressing the need to teach the language for other career purposes apart from the religious one. The study, thus, comes up with suggestions that may be useful for designing a purposeful curriculum of Arabic language for the tertiary institutions in Nigeria.
\end{abstract}

Keywords: Arabic Language Education, Nigerian tertiary institutions, Arabic Curriculum development, Effective teaching and learning

\section{Introduction}

The paper adopted a mixed-method research approach which is a pragmatic approach to a scientific research, thereby given us the opportunity to use any of the methods, techniques and procedures typically associated with quantitative or qualitative research. Different techniques were used at the same time or one after the other. For example, questionnaires were distributed to the students concerned and the findings of the questionnaires were then used to measure attitudes in a large scale sample with the aim 


\section{ELK ASIA PACIFIC JOURNAL OF SOCIAL SCIENCES}

ISSN 2394-9392 (Online); DOI: 10.16962/EAPJSS/issn.2394-9392/2014; Volume 2 Issue 1 (2015)

of carrying out statistical analysis in the appropriate manner. It is, indeed, a datadriven or data-backed research article that dishes up survey statistics, numbers, charts, graphs and all things that make information to be rich. This kind of article or research is meant only for the consumption of intelligent readers. The process of getting an accurate data for this research was guided by Tyler's theory of curriculum modelling. Tyler's model for curriculum design was developed because he felt that educational programs lacked clearly defined goals and objectives for the purpose of measuring student achievement in the course. Tyler interpreted that the vast majority of educational curriculum was defined by a sense of inflexibility and restriction, rather than goaloriented and directed learning activities. By creating the Tyler Model, he was able to succinctly and accurately outline a series of basic steps for developing curriculum that was laden with measurable and attainable educational objectives. Through the development of the Tyler Model of curriculum evaluation, there was created a "process of determining the educational effectiveness of learning experiences"). Tyler's goal attainment model or sometimes called the objectives-centered model is the basis for most common models in curriculum design, development and evaluation. The
Tyler model is comprised of four major parts. These are:

1) Defining objectives of the learning experience;

2) Identifying learning activities for meeting the defined objectives;

3) Organizing the learning activities for attaining the defined objectives; and,

4) Evaluating and assessing the learning experiences.

Therefore, Tyler's model is product focused. It evaluates the degree to which the predefined goals and objectives have been attained. The Tyler's model of curriculum design was adopted in this paper in an effort to revive the curriculum of Arabic language in the light of contemporary challenges for nation building and human development. Hence the study explores the perspectives of students in the Arabic Departments in one of the universities in the South West, Nigeria in order to find in-depth solutions to the fears raised by the students of Arabic Language in Nigeria. Thus, the Tyler's theory of Curriculum modelling is adopted as the guiding principle that could be used to solve the problems facing the Arabic Language, as raised by the students.

\section{Identified Grassroots' Problems and Misconception of the Nigerian} Society 


\section{ELK ASIA PACIFIC JOURNAL OF SOCIAL SCIENCES}

ISSN 2394-9392 (Online); DOI: 10.16962/EAPJSS/issn.2394-9392/2014; Volume 2 Issue 1 (2015)

Many people in Nigeria still nurture negative impression about the teaching and learning of Arabic language in the University. Data collected on this study and the related literature established the fact that those who study Arabic language are considered by the Nigerian society as being uncivilized because they are studying the language of Islam in the University while their counterparts are taking other courses that are considered to be lucrative and which can make them to be useful to the country. Thus, the learning of this course in the University, especially, in the in the perception of the larger Nigerian society is considered as a waste of time. In addition to that, Arabic students are always, mistakenly, taken as Islamic studies students, for they see them as nothing but spiritualists who heal people from their maladies through Arabic spiritual incantations. This fact was established by many researches carried out on the teaching of Arabic language in Nigeria (Malik, S.A, 1999; Lawal, I.A, 2006; \& Oderinde, B.B, 2007). Lawal, I.A, (2007), when giving his own personal experience says that his family members were very surprised when he came back from Libya where he had completed his undergraduate program in Arabic and told them that he wanted to go for the National Youth Service Corps (N.Y.S.C); a one year mandatory program for any Nigerian who might have completed his or her undergraduate program under the age of thirty. This kind of a national service is part of the requirements of the Nigeria Public Service Commission for anyone to be gainfully employed in any government work in Nigeria. Lawal, I.A maintained that his family hardly believed that someone like him who had studied Arabic could be recognized by the government. Malik, S.A, (1999) while making reference to the experience of ElGarh, the former Head of Department of Arabic and Islamic studies, University of Ibadan, when a female professor was introduced to him and who asked him about the length of period required for an Arabic student to graduate in the University. ElGarh, in his response, told her that it is four years. The female professor retorted with surprise by saying: "Four years? Is there anything to learn in Arabic other than these Muslim prayers". That kind of a reaction, in the opinion of the writer, is a clear manifestation of the kind of misconception the larger populace of the Nigerian society had for those who study Arabic language. In a similar vein, one of the respondents currently undergoing a degree program in Arabic had this to say:

" Why we have problem is that they (other students in other fields of learning) look at us as if we do not 
have the same status with

them as students. They

view each and every one

of us as someone who has

come to the university to

study the language of a

particular religion. Hence,

they call us alfa (a muslim

spiritualist) and labelled

us illiterates by not going

after the western

education'.

If all the evidences described above are to go by, it clearly shows that the Nigerian society is yet to recognize the importance of learning Arabic as a civilizational language. It is, therefore being conceived as a language that is of no importance to the country. It is even common among the Yoruba tribe in the Western part of Nigeria that those who opt for Arabic are lethargic and indolent students who cannot be able to go after any meaningful profession other than Arabic. The adage of which goes thus: “'Ole baati oko si ile kewu'. Meaning: “The lazy gets nothing to do rather that to opt for Arabic traditional school". Though, this adage might have contradicted another one that described learning of Arabic language as a difficult task; "Ise nla orin kewu". Meaning composing Arabic poem is a difficult task. (Lawal, A.I, 2006).

\section{Parental Influence}

It is also observed that some of those students who opt for Arabic language were influenced by the dictates of their parents. This, itself, is due to the love which their parents have for their religion; Islam. Hence the reason why some of those parents prefer their children at times, to become an Islamic scholar. As a result of this, many of the students, initially, may not have the interest of the course in mind, since it is not in their plan right from the onset. This kind of parental influence might have certain effect on the student psychological mindset and attitude towards the program.

\section{Lack of unified aims and objectives}

The objective of teaching Arabic language in Nigerian university does not have a national outlook. Each University came up with different objectives of teaching the course and this manifest in the placement of the Arabic program, as course of study in various Universities, under different Departments (Bidmos, A.B, 1997). As a result of this, the problem facing the learning of Arabic language is difficult to be solved collectively.

Political and religious Problems in the Arab and Islamic World 


\section{ELK ASIA PACIFIC JOURNAL OF SOCIAL SCIENCES}

ISSN 2394-9392 (Online); DOI: 10.16962/EAPJSS/issn.2394-9392/2014; Volume 2 Issue 1 (2015)

Among several issues baffling the mind of any Student of Arabic in Nigeria is the state and fate of socio-political and religious problems facing the Arab and the Islamic world. The belief that the Arab and Islamic world have numerous socio-political and religious problems to contend with, actually contributes to some of the challenges facing the students of Arabic in Nigeria. Several unresolved geo-political conflicts, intra, and ethno-religious conflicts, popular uprisings in the Arab countries, contemporary face-off between Islam and the West on issues like fundamentalism, extremism, terrorism as well as the emergence of Islamic State do not give the full-fledged required motivation to the students pursuing Arabic Studies. In fact, these crises have resulted in the suspension of scholarships and the admissions known to be given by some Arab and Islamic countries to the foreign students wishing to study Arabic in their countries. Even, some of the Arabic students approached on this matter expressed theirnon-willingness or readiness to further pursue their Arabic studies, especially, in the Arab world.

\section{Putting the Tyler's Theories into Test}

\section{On Curriculum Modelling and Learning}

Tyler's theory of curriculum modelling implies that special consideration should be given to the learner in terms of the learner's previous learning experience on that particular subject matter, as well as the prior knowledge of the learner and the curriculum content that may be found to suit the leaner's previous experience and knowledge. In putting this kind of a theory into test, the following themes and analyses were generated from the cross examination carried out on this particular subject-matter:

\section{Prior knowledge:}

The finding of our examination on the learner's prior knowledge shows that most of the students who usually enrolled for Arabic language in the University have good background of the four basic skills of teaching and learning a language; reading, writing, listening, and speaking. This is not unconnected with the fact that almost all of them are products of the private traditional Arabic schools. As a result of this, they always pass the courses that are taught in the program with ease, especially when such courses are delivered in Arabic language. On the other hand, the courses that are taught in English language may be difficult to comprehend for those who do not have good background in Western education (Abubakre R.D, 1984). 


\section{ELK ASIA PACIFIC JOURNAL OF SOCIAL SCIENCES}

ISSN 2394-9392 (Online); DOI: 10.16962/EAPJSS/issn.2394-9392/2014; Volume 2 Issue 1 (2015)

Although, Arabic language is a subject offered at both primary and secondary levels of Nigerian education system, but many researches carried out show that students from secondary school without good background in Arabic language always find it difficult to cope with the Arabic courses that are taught in the Universities. These set of students are usually admitted for the then syllabus ' $\mathrm{B}$ ' in Arabic language which was established at the inception of the establishment of Arabic and Islamic studies Department in the University of Ibadan (UI). This program has in many ways helped the beginners of Arabic in University because many of them later worked assiduously and make a head way in learning Arabic language (Balogun, I.I.B, 1978), as quoted in Abubakre, R.D (1984). It is pertinent to say that the said syllabus ' $\mathrm{B}$ ' produced many Christian graduate students of Arabic and one of them became a professor in Arabic language (Abubakre, R.D, 2002). However, in the current UI or other Nigerian University, this type of syllabus had been scrapped and Nigerian Universities now admit students for Arabic programme with the credence that such students must have had a good background in Arabic language before enrolling for the program. However, those students with no good background in Arabic language do not benefit from the program, although some of them may manage to graduate from the University, but they do not usually have good proficiency and competence in all the four basic skills of language. This is to say that in most cases, they may not be able to communicate effectively in Arabic language. The most unfortunate aspect of it is that some of them end up becoming Arabic teachers in primary and secondary schools while some of them become lecturers in the University despite the fact that they have lots of deficiencies in Arabic language. There are also the cases of those graduates of Arabic language that are very good in Arabic but they are not good at all in speaking English despite the fact that they are University graduates. This is one of the fundamental problems facing the Arabic language in Nigeria.

\section{Traditional Private Arabic Schools (Madrasah):}

According to Adedeji, L.L, (2006), these schools are known as Madrasah (Traditional Private Arabic Schools). They are also interchangeably used to denote schools which offer instruction in Islamic education and some secular subjects such as Geography, Mathematics, etc, using Arabic or local language as the medium of instruction. In most cases these school are owned by private proprietors or Islamic organisations. These schools are highly important for any meaningful and positive 


\section{ELK ASIA PACIFIC JOURNAL OF SOCIAL SCIENCES}

ISSN 2394-9392 (Online); DOI: 10.16962/EAPJSS/issn.2394-9392/2014; Volume 2 Issue 1 (2015)

change towards the development of Arabic language in Nigeria because these schools remain the only source of producing vibrant and competent Arabic students; they continue to serve as the main provider of students for the Universities in the field of Arabic language, Islamic law and Islamic studies. (Oladosu, A.G.A.S, 2003), Different researchers have established the importance of these schools towards the development of Arabic language and Islamic studies in Nigeria but they all held the view that the fundamental problem of these schools is the non inclusion of English language and secular subjects in their curriculum (Abubakre,R.D, 1984; Bidmos, A.I, 1997; Oladosu, A.G.A.S, 2003; Adedeji, L.L, 2006; Lawal, A.I, 2008).

These schools are not recognised by the relevant government agencies of the ministries of Education in the Southern part of the country because they have no affiliation with any government schools and they are categorised as religious schools. The problems faced by the graduates of the schools were highlighted by (Lawal, A.I, 2008), while (Bidmos, A.I, 1997) gives account of the prospects of these schools if their philosophy and objectives are to be tailored towards human capital development and Nation building. This was also the argument put forward by (Adedeji, L.L, 2006). He highlighted the havoc these schools would continue to curse to the development of the Muslims' manpower in the country if their curriculum remains stagnant without any inclusion of the modern and secular subjects. He then came up with the evaluation of the curriculum of some of the schools and designed a befitting curriculum for these schools so that they can meet up with the prevailing standard of education in Nigeria.

\section{Organization of the learning experience}

This, according to Tyler, is a kind of a situation in which the acquired learning and educational experiences are effectively organized within the context of a formidable and effective curriculum. The examination carried out for the purpose of this paper unraveled many salient issues that are very significant in the organization of the learning experience for the teaching and learning of Arabic language in Nigeria institutions of higher learning. In putting this kind of a theory into test, the following themes and analyses were generated from the cross examination carried out on this particular subject-matter:

\section{Methodology}

The methodology used in teaching will determine the effectiveness of the teacher in handling any course allocated to him. In teaching a foreign language, different 


\section{ELK ASIA PACIFIC JOURNAL OF SOCIAL SCIENCES}

ISSN 2394-9392 (Online); DOI: 10.16962/EAPJSS/issn.2394-9392/2014; Volume 2 Issue 1 (2015)

methods need to be adopted in accordance with the student's background, environment and proficiency. That is the more reason why the most crucial aspect of teaching Arabic in the Nigerian institutions of higher learning is the medium of instruction. The information gathered from the collected data reveals that English language is always used in most cases as the means of instruction by the Arabic lecturers irrespective of the mode of instruction of the course. The theoretical question that needs to be asked in this aspect is: 'Can a foreign language be used to teach another foreign language? In order to get appropriate answer to this question, different views and theories for the effective teaching of a foreign language will now be highlighted.

In this context, the first thing that needs to be established is that in teaching a second language, the language input (listening) must be higher than the expected level of language production by the pupils. This means that teachers need to develop the habit of speaking the language several times to the hearing of the student, as this will gradually becomes meaningful to the student when he listens. Chomsky (1964) developed a theory of language acquisition in which the learner is described as the generator of the language rules. To this end, his view was that learner develops acquisition of the targeted language through his own effort by combining what he had heard together to arrive at a meaningful understanding. This notion was also taken by Corder (1967) when he argued that language errors made by students indicate the development of the underlying competences. Selinker (1972) referred to the leaner's errors as the positive effort of learning new language. Krashen, S.D (1981) in his theory of communicative learning competence holds the view that language can be learnt or acquired. $\mathrm{He}$ believed that the process of language acquisition through communication is the best form by which the required competency and proficiency could be attained. $\mathrm{He}$ maintained that this process will allow the learner to develop meaningful interaction in the targeted language (natural communication); a kind of a situation in which speakers are focused, not in terms of their utterances but in terms of the level of their communication. He further opined that the only instance in which the teaching of grammar and other aspects of the targeted language can result in language acquisition and proficiency is when the students are interested in the subject and the targeted language is used as a medium of instruction (Krashen, S.D, 1981).

In a similar vein, Ricardo, S. V (1999) highlighted the views of some of the linguists on the medium of instruction in teaching a foreign language. Some of these 


\section{ELK ASIA PACIFIC JOURNAL OF SOCIAL SCIENCES}

ISSN 2394-9392 (Online); DOI: 10.16962/EAPJSS/issn.2394-9392/2014; Volume 2 Issue 1 (2015)

views, as identified by Ricardo are that of Finocchiaro and Bonomo (1973) both of who stress the importance of the role of the teacher in the class. They further present a list of sixteen (16) tasks which a good language teacher should put into practice. One of which is that teachers should use the students' native language sparingly in the classroom, but must not hesitate to use it to clarify instructions or to ensure that essential information has been understood. Apelt (1981) in his own account emphasized the crucial usage of foreign language as a medium of instruction in the classroom, but without excluding absolutely the use of the mother tongue', Sanderson (1983) provides lists of fourteen (14) characteristics of a good foreign language teacher and laid much emphasis on the principal use of the targeted language. Bailey (1985) presents the results of a classroom research on "A good language teacher". Some of the characteristics mentioned for an outstanding teacher involved the use of the targeted language by both the teacher and the students, and that with much converse in the foreign language by both the teacher and the students. The essence of all these information, as demonstrated above, shows that effective learning and teaching of a second language should involve persistent communication and interaction between the students and the teachers.

\section{Facilities}

This is another important theme in the organization of the learning experience. An effective teaching and learning of a modern foreign language need to give much consideration to the Computer Assisted Language Learning (CALL) which is a systematic way of studying and uses of computer applications in language teaching and learning. It is, in fact, a growing field in Information and Learning Technology (ILT), with a wide selection and collection of applications, reference works, study and research tools for effective teaching and learning of a foreign language. The teachers of Arabic language need to familiarize themselves with this new approach of teaching, and they must also adopt it in their methodology of teaching. The new technology for the teaching of language has tremendous advantage and impact on the development of the learning competence and proficiency of the student. Among these benefits, as highlighted by Kuang-wu Lee (2000) are: (a) experiential learning (b) motivation (c) student achievement enhancement (d) provision of authentic materials for studying (e) greater interaction, (f) individualization, ( $\mathrm{g}$ ) independence from a single source of information, and (h) Access to global understanding. Therefore, teaching of Arabic as a foreign language 


\section{ELK ASIA PACIFIC JOURNAL OF SOCIAL SCIENCES}

ISSN 2394-9392 (Online); DOI: 10.16962/EAPJSS/issn.2394-9392/2014; Volume 2 Issue 1 (2015)

should be moved away from the traditional system of teaching and be made to tow the modern line and approach of systematic learning. He also analyzed some of the difficulties that a teacher of language may face in an effort to applying the new technology approach. These are; (a) financial difficulty (b) non-availability or inadequacy of computer hardware and software (c) technical and theoretical knowledge hindrances, and (d) nonacceptance of the technology, especially at the initial stage, from the students who are already familiar with the traditional system of teaching.

\section{Contemporary Effort and Approach}

One of the contemporary approaches to enhance the learning of Arabic in Nigeria is the introduction of Arabic village, wisely known as the Nigerian Arabic village; it is one of the programs designed by the Federal Government of Nigeria to enhance the Arabic students' proficiency in the speaking of Arabic language. The village was established as a mini university campus for Arabic students in the tertiary institutions to spend there, at least, one semester during their course of study. The primary objective of this village is to enable the students to familiarize themselves with Arabic culture and way of life. It is situated in a town called Ingala, Borno State, Nigeria; an area predominantly resided by the Shuwa Arabs who share and espouse almost the same socio-cultural settings with the Arabs. However, despite the lofty ideas behind the setting up of the village, it has to be reiterated here that the village continues to contend with several challenges; principal among them is its geographical location in a place considered to be the most isolated and remote area in Nigeria, that of which mostly affect the Arabic students' motivation to attend the village.

\section{Conclusion}

This research has clearly revealed the salient issues affecting the teaching and learning of Arabic language in Nigeria. Our findings show the urgent need to address the fear raised by the students of Arabic in this paper whenever there is that ample opportunity to redesign the Arabic curriculum for the Nigerian Universities, and this should be done in such a way that it should be designed to creating opportunities for gainful employment and contributing to National development. In addition to that, the Universities running Arabic programs in Nigeria must ensure that competent personnel and experts are employed to handle the subjects, while adequate and contemporary teaching and learning facilities should be provided to aid the 


\section{ELK ASIA PACIFIC JOURNAL OF SOCIAL SCIENCES}

ISSN 2394-9392 (Online); DOI: 10.16962/EAPJSS/issn.2394-9392/2014; Volume 2 Issue 1 (2015)

students. It is, therefore, suggested that the Tyler's theories on curriculum modeling, learning experience and its effectual organization, as demonstrated in the course of this paper, should serve as the guiding principle for the actualization of these noble ideals. It is the hope of the writers that implementation of these suggestions and many other more will go a long way to resolve some of the problems facing both the teachers and students of Arabic language in Nigeria.

\section{References}

[1] Abubakre, R.D, (2002). Survival of Arabic in Difficult Terrains. Ilorin: Unilorin Press.

[2] Abubakre, R.D, (1984). The Future of Arabic Learning in Yoruba land. Ilorin Journal of

Education. Vol., 4.

[3] Adedeji, L.L, (2006). An Evaluation of the Curricula of Private Arabic School in

South- West of Nigeria: A Design of a New Curriculum. Unpublished $\mathrm{PhD}$ thesis: University

of Lagos.
[4] Ahmed, I. P. (2008). Evaluation of Arabic Language Software Program. Malaysia:

International Islamic University Press.

[5] Alcroft, J. (2002). Illuminative Evaluation for Design Educators using Critical Trialling.

Retrieved 26 $6^{\text {th }} \quad$ February 2012, http://www.palatine.ac.uk/files/832.pdf.

[6] Al-Ilori, (1978). Al-Islam fi Naijiriya wa Shaykh 'Uthman bn Fodio al-Fulani. Agege: Markaz

Press.

[7] Barllint, M, (2010). Assessing Students' Perceived Language Needs in a needs' Analysis.

Retrieved from www.paaljapan.org/resources/proceeding/P AAL/....Balmt Martin.pdf. Accessed on 23 ${ }^{\text {rd }}$ Dec., 2011.

[8] Berlett, M.S, (1954). A Note on the Multiplying Factors for Various Chi-Square Approximations. Journal of the Royal Statistical Society. (16 series B).

[9] Bidmos, M. A. (1996). Mustaqbal lLugatil 'Arabiya fi Naijiriya. Lagos: Islamic Publication

Bureau. 
Happer Colling College Publisher.

[10] Bodgan, R.C, \& Biklen, S.K, (1992).

Qualitative Research for Education: An

Introduction to

Theory and Methods. Bsston: Ally \& Bacon.

[11] Corder, S.P, (1967). The Significance of Learners' Error. International Review of Applied

$$
\text { Linguistics. Vol., } 5 .
$$

[12] Creswell, J.W, (2007). Qualitative Inquiry and Research Design ( $\left.2^{\text {nd }} \mathrm{ed}.\right)$, Singapore: C.O.S

Printer Press Ltd.

[13] Cronbach, L. J. (1982). Designing Evaluations of Educational and Social Programs. San

Francisco: Jossey-Bass.

[14] Darussalam, G. (2010). Program Evaluation in Higher Education. The Intelectual Journal

Research and Review, vol. 5 (2). Time Taylor International. Retrieved on $23^{\text {rd }}$ Nov., 2011.

[15] Dick, W \& Kerey, L, (1996). The Systematic Design of Instruction (4 $\left.{ }^{\text {th }} \mathrm{ed}.\right)$, New York:
Doryei, (2003).

[16] Fafunwa, A.B, (1974). History of Education in Nigeria. London: George Allen \& Unwin.

$$
\text { Nov., } 2011 .
$$

[17] Foncchairo, M \& Bonomo, M. (1973). The Foreign Language Learner. New York: Regent

Publishing Co. Gardner \& Lambert, (1975).

[18] Galadanchi, S. (1978). Harakatul Lugatul-Arabiyya wa Adabiha fi Naijiriya $\min 1804-1966$.

Cairo :Darul Ma’arif.

[19] Glatthorn, (2005). Foundation of Curriculum. Retrieved from www.sageb.com/...6041chpater_1_Glatthorn_ (sage) _1_ proof on $23^{\text {rd }}$ Sept., 2010.

[20] Grafffiths, M \& Parr, M. (2001). Language - Learning Strategies: Theories and Perception.

ELT Journal, Vol. 53 (3), Oxford University Press. Retrieved on $23^{\text {rd }}$ Sept., 2011. 
[21] English for Specific Purposes. Issue 31,

Vol. 10. Retrieved from www.espworldinfo/article.com.

[22] Krashen, S.D, (1981). Principles and Practice in Second Language Acquisition. London:

English Language Teaching Series.

[23] Lawal, A.I, (2007). Of Tongue and its Numerous "Faces" - The History of Arabic in Nigeria.

Lagos: LASU Press.

[24] Lynch, B. (1996). Language Program Evaluation: Theory and Practice: Cambridge University Press.

[25] Maliki, S.A, (1999). Arabic, the Muslim Prayer and Beyond. Ibadan: University Press. Miles \& Huberman, (1994).

[26] Oderinde, B. (2007). English and Arabic Curriculum Context: Benefits to Nigerian Society.

Lagos: Lagos State University Press.

[27] Ogunbiyi, A, (2003). An Unfamiliar Guest in a Familiar Household. (Sanni, ed.), Lagos:

Debo Prints.
[28] Oladosu, A.G.A.S, (2003). 'Idatul alNaza'ir fi Minihaji al-Madarisi al- 'Arabiya al-Khasa Fi

Biladi Yoruba. (Sanni, ed.), in $A n$ Unfamiliar Guest in a Familiar Household. Lagos: Debo

Prints.

[29] Onwuegbuzie, A. J., \& Teddlie, C. (2003). A Framework for Analyzing Data in Mixed

Methods Research. In Tashakkori. A \& Teddlie. C (Eds.), Handbook of Mixed Methods in

Social and Behavioural Research (pp. 351-383). Thousand Oaks, CA: Sage.

[30] Richard, J.C, (2001). Curriculum Development in Language Needs. Oxford: Pergomom /

Council of Europe. In Khajavi \& Gordani, (2010).

[31] Smith and Osborn, (2007). Interpretive Phenomenological Analysis in Doing Social Psychology Research. (ed. G.M. Blackkwell). Oxford U.K: The British Psychological Society and Blackwell Publishing Ltd. 


\section{ELK ASIA PACIFIC JOURNAL OF SOCIAL SCIENCES}

ISSN 2394-9392 (Online); DOI: 10.16962/EAPJSS/issn.2394-9392/2014; Volume 2 Issue 1 (2015)

[32] Tyler, R. (1969). Basic Principle of Curriculum and Instruction. Chicago \&

London: The

University of Chicago press. Wesely, (2010).

[33] Yahyah, T.M, (1986). A study of the Structural and Thematic Innovation in the Arabic Poetry

of Kanemi-Bornu Empire in the Works of al-Tahir bn Ibrahim al Fullati and Yusuf b. Abdul-

Qahir, al-Qarghri. Unpublished $\mathrm{PhD}$ thesis, University of Ibadan. 